\title{
MANFAAT EKONOMI DAN DAYA DUKUNG KAWASAN PANTAI LOMBANG KABUPATEN SUMENEP PROVINSI JAWA TIMUR
}

\author{
Norita Vibriyanto, ${ }^{1 *}$ Ahyar Ismail ${ }^{2}$, Meti Ekayani ${ }^{2}$ \\ ${ }^{1}$ Program Studi Sumberdaya dan Lingkungan, Sekolah Pascasarjana \\ Institut Pertanian Bogor (IPB), Bogor 16680 \\ *Email: norita.vibriyanto@gmail.com \\ Departemen Ekonomi Sumberdaya dan Lingkungan, Fakultas Ekonomi dan Manajemen \\ Institut Pertanian Bogor (IPB), Bogor 16680
}

\begin{abstract}
RINGKASAN
Pantai Lombang memiliki manfaat ekonomi dan manfaat ekologi. Manfaat ekonomi berupa Pendapatan Asli Daerah (PAD) dari retribusi yang dipungut sedangkan manfaat ekologi merupakan manfaat yang diperoleh dari keberadaan cemara udang yang ada di sepanjang bibir pantai yaitu berupa wind break dan mencegah terjadinya tsunami. Peningkatan jumlah pengunjung wisata pantai Lombang setiap tahunnya berdampak positif terhadap perekonomian yaitu peningkatan PAD. Namun, peningkatan kunjungan yang tidak terkendali dapat merugikan lingkungan wisata pantai, yaitu berupa rusaknya ekosistem cemara udang di pantai Lombang. Apabila ekosistem pantai rusak maka keindahan pantai akan berkurang dan dapat menyebabkan jumlah kunjungan wisatawan berkurang. Dalam kondisi ini akan terjadi trade off antara kepentingan ekonomi dan ekologi. Oleh karena itu penelitian terhadap manfaat ekonomi dan dukung kawasan (DDK) Pantai Lombang perlu dilakukan. Hal ini dimaksudkan agar kegiatan wisata dapat berjalan tanpa mengabaikan kelestarian cemara udang dan memberikan manfaat ekonomi. Manfaat ekonomi yang tinggi menunjukkan Pantai Lombang sebagai wisata alam memiliki jasa lingkungan yang sangat penting bagi ekonomi masyarakat. Sumberdaya alam dan keindahan Pantai Lombang harus dijaga untuk keberlangsungan wisata alam, karena tanpa keindahan dan konservasi lingkungan tidak akan ada aktivitas wisata, dan itu berarti tidak ada manfaat ekonomi bagi masyarakat.
\end{abstract}

Kata kunci: daya dukung, manfaat ekonomi, Pantai Lombang, wisata alam

\section{PERNYATAAN KUNCI}

- Peningkatan jumlah wisatawan berdampak positif terhadap peningkatan PAD, akan tetapi peningkatan jumlah wisatawan dapat berdampak negatif pada lingkungan fisik wisata.
- Mengingat tingginya jumlah kunjungan saat hari libur (peak season) dibandingkan hari biasa (low season) berpotensi untuk mengalami over carrying capacity yang dapat berdampak negatif terhadap lingkungan sehingga kajian terhadap segmentasi harga perlu dilakukan. 
- Segmentasi harga wisata dimaksudkan untuk memecah jumlah pengunjung saat peak dan low season, diharapkan pengunjung yang tidak bersedia membayar tinggi pada saat peak season dapat berwisata pada saat low season dengan harga lebih rendah, sehingga kelestarian lingkungan lebih terjaga.

\section{REKOMENDASI KEBIJAKAN}

- Kegiatan wisata Pantai Lombang memberikan manfaat ekonomi yang tinggi sehingga kegiatan wisata Pantai Lombang perlu dipertahankan.

- Beberapa hal yang dapat dilakukan untuk mempertahankan kegiatan wisata Pantai Lombang yaitu kegiatan konservasi cemara udang, wisata berbasis lingkungan, penerapan daya dukung kawasan dan peran aktif dari Pemerintah Kabupaten Sumenep melalui peningkatan bantuan pengembangan dan pemeliharaan sarana dan prasarana.

- Pemberlakuan segmentasi harga tiket wisata pada saat peak dan low season untuk mengatasi over carrying capacity pada saat-saat peak season yang dapat mengakibatkan degradasi lingkungan Pantai Lombang.

\section{PENDAHULUAN}

Wisata alam merupakan salah satu kegiatan yang perlu dikembangkan dalam mendukung pembangunan berkelanjutan (Ekayani, 2004; Ekayani dan Nuva, 2013).

Pantai Lombang merupakan salah satu objek wisata andalan Kabupaten Sumenep yang memberikan kontribusi tertinggi terhadap Pendapatan Asli Daerah (PAD), jika dibanding- kan dengan dua objek wisata lain yang dikelola oleh Pemerintah Kabupaten Sumenep (Disbudparpora Kabupaten Sumenep, 2014). Besarnya Pendapatan Asli Daerah (PAD) dari objek wisata Pantai Lombang pada tahun 2012 hingga 2013 berturut turut Rp 56.900.000 dan Rp 70.450.000. Hamparan pasir putih yang luas dan dirimbuni cemara udang merupakan ciri khas wisata Pantai Lombang yang berjarak $30 \mathrm{~km}$ dari kota Sumenep.

Pantai Lombang selain memiliki potensi wisata yang dapat memberikan manfaat ekonomi bagi pemerintah dan masyarakat, juga memiliki manfaat ekologis sebagai wind break dari adanya cemara udang (Casuarina equisetifolia) di sepanjang pantai. Sebagai wind break, cemara udang dapat melindungi tanaman palawija milik petani dari tiupan angin pantai. Hal ini sejalan dengan apa yang dikemukan oleh Syahbudin et al. (2012) dan Ganesan (2005) dalam De Zoysa (2008) bahwa cemara udang berfungsi sebagai wind break. Selain itu pantai Lombang yang merupakan kawasan pantai yang berhubungan langsung dengan Laut Jawa berpotensi terkena tsunami dari gunung laut terdekat, seperti dari Laut Maluku ataupun Laut Banda, sehingga keberadaan cemara udang dapat berfungsi untuk mengurangi dampak gelombang tsunami (Ganesan, 2005 dalam De Zoysa, 2008; Thuy et al., 2012).

Mengingat tingginya jumlah kunjungan wisata saat hari libur (peak season) dibandingkan hari biasa (low season) berpotensi mengakibatkan over carrying capacity yang berdampak negatif pada lingkungan berupa degradasi lingkungan yang dapat menimbulkan bencana alam dan hilangnya kegiatan wisata alam. Agar lingkungan wisata tetap terjaga maka perlu dilakukan kajian tentang manfaat ekonomi dari kegiatan wisata, daya dukung kawasan, dan perlunya penerapan segmentasiwisata. 


\section{SITUASI TERKINI}

Masyarakat yang melakukan kegiatan usaha wisata di Pantai Lombang terdiri dari pedagang reguler dan pedagang musiman. Pedagang reguler adalah pedagang yang selalu ada di dalam kawasan wisata Pantai Lombang. Pedagang musiman merupakan pedagang yang sewaktu-waktu ada di dalam objek wisata Pantai Lombang, misalnya hanya berjualan pada hari raya Idul Fitri atau perayaan tertentu selebihnya mereka berjualan atau melakukan aktivitas di luar kawasan objek wisata Pantai Lombang. Kegiatan wisata Pantai Lombang memberikan kontribusi bagi ekonomi masyarakat setempat (Tabel1).

Menurut Soehadji (1995) pendapatan yang memberikan kontribusi 70\% sampai 100\% dari total pendapatan adalah jenis usaha pokok yang merupakan pendapatan utama pedagang. Berdasarkan Tabel 1 kontribusi (share) pendapatan dari wisata terhadap pendapatan total pedagang reguler sebesar 94,45\%. Hal ini sebagai indikasi bahwa keberadaan Pantai Lombang memberikan peranan penting, dimana usaha wisata merupakan penghasilan utama bagi pedagang reguler, sedangkan jenis usaha yang dilakukan oleh pedagang musiman di Pantai Lombang adalah usaha sampingan dengan kontribusi pendapatan dari wisata $<30 \%$.

Luas kawasan Pantai Lombang yang dapat dimanfaatkan untuk melakukan aktivitas rekreasi pantai adalah $15.000 \mathrm{~m}^{2}$ (panjang pantai 300m dan lebar $50 \mathrm{~m}$ ). Mengacu pada rumus Yulianda et al. (2010) maka dapat dihitung carrying capacity aktivitas rekreasi pantai yang dilakukan di Pantai Lombang (Tabel 2). DDK yang dihitung hanya DDK fisik yang didasarkan pada kenyamanan pengunjung terhadap ruang dan waktu yang dibutuhkan untuk berwisata alam pantai, belum memperhitungkan daya dukung ekonomi dan sosial.

Berdasarkan informasi Tabel 2, Pantai Lombang memiliki daya dukung kawasan 200 orang/hari. Artinya, dalam waktu yang bersamaan, dengan total waktu 10 jam yang disediakan kawasan selama 1 hari, dan waktu yang digunakan wisatawan untuk kegiatan wisata pantai selama 3 jam, maka jumlah yang dapat ditampung pada lokasi tersebut adalah 200 orang.

Tabel 1. Kontribusi pendapatan pedagang di Pantai Lombang terhadap total pendapatan

\begin{tabular}{|c|c|c|c|c|}
\hline \multirow{2}{*}{ Jenis pedagang } & \multicolumn{2}{|c|}{ Pendapatan (Rp) } & \multirow[b]{2}{*}{ Total (Rp) } & \multirow{2}{*}{$\begin{array}{l}\text { Kontribusi (share) } \\
\text { pendapatan wisata } \\
\text { terhadap total } \\
\text { pendapatan } \\
(\% / \text { tahun })\end{array}$} \\
\hline & Wisata & Non wisata & & \\
\hline (a) & (b) & (c) & $(\mathrm{d}=\mathrm{b}+\mathrm{c})$ & $(e=b / d * 100 \%)$ \\
\hline \multicolumn{5}{|l|}{ A. Reguler } \\
\hline 1. Warung makanan & 37.972 .000 & 6.040 .000 & 44.012 .000 & 90,86 \\
\hline 2. Jasa berkuda & 55.733 .333 & 6.333 .333 & 62.066 .666 & 89,70 \\
\hline 3. Toilet & 3.600 .000 & 0 & 3.600 .000 & 100,00 \\
\hline 4. Parkir & 19.060 .000 & 800.000 & 19860.000 & 98,26 \\
\hline Rata-rata & 29.091 .333 & 3.293 .333 & 32.384 .666 & 94,45 \\
\hline \multicolumn{5}{|l|}{ B. Musiman } \\
\hline Warung makanan & 1.925 .000 & 12.484 .375 & 14.409 .375 & 18,75 \\
\hline
\end{tabular}


Tabel 2. Perhitungan daya dukung kawasan

\begin{tabular}{|c|c|c|c|c|c|c|}
\hline \multirow{2}{*}{ Kriteria } & K & $\operatorname{Lp}\left(\mathrm{m}^{2}\right)$ & $\mathrm{Lt}\left(\mathrm{m}^{2}\right)$ & Wp (jam/hari) & Wt (jam/hari) & $\begin{array}{l}\text { DDK (orang) } \\
\mathrm{ax}(\mathrm{b} / \mathrm{c}) \times(\mathrm{d} / \mathrm{e})\end{array}$ \\
\hline & (a) & (b) & (c) & (d) & (e) & (f) \\
\hline DDK per hari & 1 & 15.000 & 250 & 10 & 3 & 200 \\
\hline DDK per bulan & & & & & & 6.000 \\
\hline DDK per tahun & & & & & & 72.000 \\
\hline
\end{tabular}

Sumber: (a) Yulianda et al. 2010; (b) Disbudparpora Kabupaten Sumenep 2015; (c),(d), (e) data primer

Keterangan:

DDK= Daya dukung kawasan (orang)

$\mathrm{K}=$ Potensi ekologis pengunjung per satuan unit area

$\mathrm{Lp}=$ Luas area atau panjang area yang dimanfaatkan $\left(\mathrm{m}^{2}\right)$

$\mathrm{Lt}=$ Unit area untuk kategori tertentu $\left(\mathrm{m}^{2}\right)$

$\mathrm{Wp}=$ Waktu yang disediakan kawasan untuk kegiatan wisata dalam 1 hari (jam/hari)

$\mathrm{Wt}=$ Waktu yang dihabiskan oleh pengunjung untuk setiap kegiatan tertentu (jam/hari)

Tabel 3. Jumlah wisatawan Pantai Lombang tahun 2014

\begin{tabular}{lrrrl}
\hline Bulan & $\begin{array}{l}\text { Jumlah } \\
\text { pengunjung }\end{array}$ & $\begin{array}{c}\text { DDK/bulan } \\
\text { (orang) }\end{array}$ & Persentase & Keterangan \\
\hline Januari & (a) & (b) & $(\mathrm{c}=\mathrm{a} / \mathrm{b} * 100 \%)$ & \\
Februari & 2.800 & 6.000 & 46,7 & Under carrying capacity \\
Maret & 1.930 & 6.000 & 32,2 & Under carrying capacity \\
April & 1.500 & 6.000 & 25,0 & Under carrying capacity \\
Mei & 4.644 & 6.000 & 77,4 & Under carrying capacity \\
Juni & 5.150 & 6.000 & 85,8 & Under carrying capacity \\
Juli & 6.500 & 6.000 & 108,3 & Over carrying capacity \\
Agustus & 450 & 6.000 & 7,5 & Under carrying capacity \\
September & 2.400 & 6.000 & 40,0 & Under carrying capacity \\
Oktober & 2.650 & 6.000 & 44,2 & Under carrying capacity \\
November & 1.617 & 6.000 & 27,0 & Under carrying capacity \\
Desember & 1.040 & 6.000 & 17,3 & Under carrying capacity \\
\hline Dalam 1 & 7.009 & 6.000 & 116,8 & Over carrying capacity \\
tahun & 37.690 & 72.000 & 52,35 & Under carrying capacity \\
\hline
\end{tabular}

Sumber: Disbudparpora dan UPT Pantai Lombang 2015

Secara umum jumlah kunjungan di Pantai Lombang belum over carrying capacity, kecuali pada saat peak season pada bulan Juni dan Desember. Tabel 3 menunjukkan jumlah rata-rata kunjungan pada Tahun 2014 setiap bulannya, sebesar yaitu 52,35\% dari DDK, namun pada waktu peak season di bulan Juni dan Desember sudah over carrying capacity (Tabel 3). Hal ini disebabkan bulan Juni 2014 bertepatan dengan hari libur sekolah sehingga banyak pelajar memanfaatkan waktu liburannya untuk berkunjung ke Pantai Lombang. Selain itu, masyarakat setempat memiliki kepercayaan bahwa mandi di laut pada bulan Sya'ban dapat "membuang sial" dan bulan Sya'ban pada tahun 2014 jatuh pada bulan Juni. Jumlah wisatawan pada bulan Desember yang tinggi disebabkan oleh perayaan Natal dan Tahun Baru yang diselenggarakan selama tujuh hari dimana 
Tabel 4. Jumlah pengunjung hari Natal 2014 dan Tahun Baru 2015

\begin{tabular}{lllllll}
\hline Event & $\begin{array}{l}\text { Jumlah } \\
\text { (hari) }\end{array}$ & $\begin{array}{l}\text { Jumlah } \\
\text { pengunjung } \\
\text { selama event }\end{array}$ & $\begin{array}{l}\text { Jumlah } \\
\text { pengunjung / } \\
\text { hari }\end{array}$ & $\begin{array}{l}\text { DDK/ } \\
\text { hari }\end{array}$ & Persentase & Keterangan \\
\hline & (a) & (b) & $(\mathrm{c}=\mathrm{b} / \mathrm{a})$ & $(\mathrm{d})$ & $(\mathrm{e}=\mathrm{c} / \mathrm{d} * 100 \%)$ & \\
\hline $\begin{array}{l}\text { Natal dan } \\
\text { tahun } \\
\text { baru }\end{array}$ & 10 & 8656 & 866 & 200 & $433 \%$ & $\begin{array}{l}\text { Over carrying } \\
\text { capacity }\end{array}$ \\
\hline
\end{tabular}

Sumber: UPT Pantai Lombang 2015

saat perayaan natal dilaksanakan beberapa pertunjukan diselenggarakan sehingga menarik minat wisatawan untuk berkunjung (Tabel 4).

\section{ANALISIS DAN ALTERNATIF SOLUSI}

Kondisi over carrying capacity pada saat peak season dapat membahayakan kelestarian lingkungan Pantai Lombang yang dapat menurunkan kualitas lingkungan tersebut, khususnya kelestarian cemara udang (Casuarina equisetifolia) sebagai wind breaker. Pada akhirnya penurunan kualitas lingkungan tersebut juga akan mempegaruhi keberlanjutan wisata alam Pantai Lombang. Jumlah pengunjung akan menurun seiring dengan degradasi lingkungan yang akan mengakibatkan turunnya manfaat ekonomi bagi pemerintah dan masyarakat setempat.

Salah satu upaya mengatasi over carrying capacity dapat dilakukan segmentasi harga saat peak dan low season. Harga tiket pada peak season ditetapkan lebih tinggi daripada harga tiket low season. Penentuan harga tiket pada peak season dapat ditetapkan sesuai dengan Willingness to Pay (WTP) pengunjung untuk membayar lebih sedangkan pada saat low season ditetapkan harga tiket yang berlaku saat ini. Diharapkan adanya distribusi jumlah pengunjung yang lebih berimbang pada saat peak season dan low season karena pengunjung yang tidak bersedia membayar lebih dapat berkunjung dengan harga biasa pada saat low season. Tabel 5 menunjukkan distribusi responden yang menjawab tidak bersedia membayar lebih pada masing-masing bid. Nilai expected WTP yang diperoleh dengan menggunakan metode turnbullyang mengacu pada Fauzi (2014) sebesar Rp 4.010, dengan perhitungan sebagai berikut:

$$
\begin{aligned}
\mathrm{E}(\mathrm{WTP})= & \sum_{\mathrm{j}=0}^{\mathrm{M}} \mathrm{B}_{\mathrm{j}}\left(\mathrm{F}_{\mathrm{j}+1}-\mathrm{F}_{\mathrm{j}}\right)=\sum_{n=1}^{\infty o}\left(B_{j} f_{j}^{*}\right) \\
\mathrm{E}(\mathrm{WTP})= & (2000 * 0,17)+(3000 * 0,03)+(4000 * 0,27) \\
& +(5000 * 0,50)=4010
\end{aligned}
$$

Keterangan:

$\mathrm{B}_{\mathrm{j}}=$ Lelang $/$ bid

$\mathrm{F}_{\mathrm{i}}=$ Proporsi distribusi "tidak"

$f_{*_{j}}=$ Nilai $F_{j+1}-F_{j}$

Estimasi PAD dihitung dari penerimaan tiket masuk. Asumsi yang digunakan dalam penelitian ini adalah responden yang bersedia membayar sesuai tarif tiket peak season minimal Rp 4.000 akan datang di peak season sedangkan responden yang memiliki WTP dibawah Rp 4.000 akan datang di low season. Berdasarkan perhitungan WTP (Tabel 6) maka jumlah wisatawan yang digunakan dalam mengestimasi PAD dengan segmentasi harga tiket tertera pada Tabel 6.

Penerapan segmentasi menyebabkan adanya distribusi wisatawan dari peak season ke low season yaitu penurunan jumlah wisatawan pada peak season 3.678 orang sedangkan pada low season terjadi peningkatan jumlah wisatawan 3.366 orang 
Tabel 5. Penentuan harga tiket yang sebaiknya diterapkan di Pantai Lombang pada peak season

\begin{tabular}{|c|c|c|c|c|}
\hline Lelang/Bid (Rp) & $\begin{array}{l}\text { Jumlah respon "tidak" } \\
(\mathrm{Nj}) \text { (orang) }\end{array}$ & $\begin{array}{l}\text { Total respon } \\
\left(T_{j}\right) \text { (orang) }\end{array}$ & $\begin{array}{l}\text { Distribusi } \\
\text { "tidak" }\left(\mathrm{F}_{\mathrm{i}}\right)\end{array}$ & Nilai $f_{j} *=\left(F_{j+1}-F_{j}\right)$ \\
\hline (a) & (b) & (c) & $(d=b / c)$ & (e) \\
\hline 2000 & 1 & 30 & 0,03 & 0,03 \\
\hline 3000 & 6 & 30 & 0,20 & 0,17 \\
\hline 4000 & 7 & 30 & 0,23 & 0,03 \\
\hline 5000 & 15 & 30 & 0,50 & 0,27 \\
\hline$>5000$ & & & 1 & 0,50 \\
\hline Jumlah & 29 & 120 & & \\
\hline
\end{tabular}

Tabel 6. Keragaan wisatawan

\begin{tabular}{lccc}
\hline Kriteria & $\begin{array}{c}\text { Jumlah responden } \\
\text { (orang) }\end{array}$ & $\begin{array}{c}\text { Persentase } \\
(\%)\end{array}$ & Jumlah wisatawan (orang) \\
\cline { 2 - 4 } & $(\mathrm{a})$ & $(\mathrm{b}=\mathrm{a} / \mathrm{c})$ & $\left(\mathrm{d}=\mathrm{b}^{*} \mathrm{e}\right)$ \\
\hline A. Tidak akan berkunjung & 1 & 0,83 & 312 \\
B. Berkunjung & & & \\
$\quad$ Low season & 66 & 55,00 & 20.730 \\
$\quad$ Peak season & 53 & 44,17 & 16.648 \\
\hline Jumlah & 120 & 100 & 37.690 \\
\hline Sumber: (a) Tabel 6; (c)total responden WTP yaitu 120; (e) jumlah wisatawan pada tahun 2014 yaitu 37690 &
\end{tabular}

sehingga di peak season dan low season tidak over carrying capacity dan aman untuk lingkungan (Tabel 7). Penerapan segmentasi harga tiket wisata Pantai Lombang juga mengakibatkan perubahan PAD. Meskipun terjadi penurunan wisatawan akan tetapi jika menerapkan segmentasi harga tiket, PAD yang diperoleh Pemerintah Kabupaten Sumenep lebih menguntungkan yaitu 43,34\% lebih besar dibandingkan tidak menerapkan segmentasi (Tabel 7). Hal ini sejalan dengan kajian Stele (1995) yang menyatakan bahwa segmentasi harga pada wisata adalah cara yang efektif untuk meningkatkan penerimaan. Selain itu manfaat lain yang diperoleh dengan menerapkan segmentasi wisata yaitu keberlanjutan wisata alam dan menjaga lingkungan (Zografor dan Allcroft, 2007; Park dan Yoon, 2009; Ekayani dan Nuva, 2013).
Penerapan harga tiket wisata tanpa segmentasi maupun dengan segmentasi dapat memenuhi biaya operasional pemeliharaan sarana dan prasarana objek wisata pantai Lombang sebesar 50 juta. Tambahan PAD yang diperoleh jika menerapkan segmentasi harga tiket yaitu adanya biaya yang dapat dialokasikan untuk biaya konservasi. Hal ini sejalan dengan hasil kajian Ekayani et al. (2014). Konservasi yang dimaksud dalam penelitian ini adalah konservasi cemara udang. Biaya konservasi tersebut dapat dialokasikan untuk kegiatan pembibitan, peremajaan dan pemeliharaan. Jadi, segmentasi harga tiket wisata dapat membantu mengatasi over carrying capacity sehingga wisata Pantai Lombang dapat berjalan tanpa mengabaikan kelestarian lingkungan dan tetap memberikan manfaat ekonomi. 
Tabel 7. Estimasi PAD tanpa segmentasi dan dengan segmentasi

\begin{tabular}{|c|c|c|c|}
\hline \multirow[t]{2}{*}{ Kondisi } & \multirow{2}{*}{$\begin{array}{l}\text { Tarif tiket } \\
\text { (Rp) } \\
\text { (a) }\end{array}$} & \multirow{2}{*}{$\begin{array}{c}\begin{array}{c}\text { Estimasi jumlah } \\
\text { wisatawan } \\
\text { (orang/tahun) }\end{array} \\
\text { (b) }\end{array}$} & \multirow[t]{2}{*}{ Estimasi PAD (Rp) } \\
\hline & & & \\
\hline \multicolumn{4}{|l|}{ Tanpa Segmentasi } \\
\hline Peak season & 2.000 & 20.326 & 40.652 .000 \\
\hline Low season & 2.000 & 17.364 & 34.728 .000 \\
\hline Jumlah (d) & & 37.690 & 75.380 .000 \\
\hline \multicolumn{4}{|l|}{ Segmentasi } \\
\hline Peakseason & 4.000 & 16.648 & 66.592 .000 \\
\hline Low season & 2.000 & 20.730 & 41.460 .000 \\
\hline Jumlah (e) & & 37.378 & 108.052 .000 \\
\hline \multicolumn{4}{|c|}{$\begin{array}{l}\text { Perubahan pengunjung jika segmentasi } \\
\text { diterapkan }\end{array}$} \\
\hline Peak season & & -3.678 & \\
\hline Low season & & 3.366 & \\
\hline $\begin{array}{l}\text { Tambahan PAD jika menerapkan } \\
\text { segmentasi }(\mathrm{f}=\mathrm{e}-\mathrm{d})\end{array}$ & & & 32.672 .000 \\
\hline $\begin{array}{l}\text { Persentase tambahan PAD } \\
(\mathrm{g}=\mathrm{f} / \mathrm{d} * 100 \%)\end{array}$ & & & $43,34 \%$ \\
\hline
\end{tabular}

\section{REFERENSI}

De, Zoysa, M. 2008. Casuarina coastal forest shelterbelts in Hambantota City, Sri Lanka: assessment of impacts. Small-scale Forestry, 7(1) 2008: pp 17-27.

[Disbudparpora] Dinas Kebudayaan Pariwisata, Pemuda dan Olah Raga Kabupaten Sumenep. 2014. Data Wisata. Tidak diterbitkan.

Ekayani, M. 2004. Multipurpose management of ex-situ conservation, case of Bogor Botanical Garden, Indonesia, Master Thesis, Faculty of Forest Science and Forest Ecology, University of Göttingen, Germany.

Ekayani, M., Nuva, Yasmin R., Sinaga F., Maaruf L. 2014. Wisata alam taman nasional Gunung Halimun Salak: solusi kepentingan ekologi dan ekonomi. Jurnal Ilmu Pertanian Indonesia (JIPI), 19(1) 2014: pp 29-37.

Ekayani, M., Nuva. 2013. Economic of Ecotourism (book chapter, p: 192-213). Opportunity and Challanges of Ecotourism in ASEAN Countries. Jungmin Publishing: Seoul.

Fauzi, A. 2014. Valuasi Ekonomi dan Penilaian Kerusakan Sumberdaya Alam dan Lingkungan. IPB Press: Bogor.

Park, D., Yoon Y. 2009. Segmentation by motivation in rural tourism: a Korean case study. Tourism Management, 30(1) 2009: pp 99-108.

Soehadji. 1995. Pengembaangan Bioteknologi Peternakan: Keterkaitan Penelitian, Pengkajian dan Aplikasi. Proceeding. 
Lokakarya Bioteknologi Peternakan. Thuy N., Tanaka N., Tanimoto K. 2012. Tsunami

Departemen Peternakan dan Kantor

Menteri Negara Riset dan Teknologi,

Koordinator Jaringan Kerja, Pengembang-

an Bioteknologi Peternakan.

Steele, P. 1995. Ecotourism: an economic analysis.

Journal of Sustainable Tourism, 3(1) 1995: pp 29-44.

Sunaryo, B. 2013. Kebijakan Pembangunan Destinasi Pariwisata Konsep dan Aplikasinya di Indonesia. Gava Media: Yogyakarta.

Syahbudin, A., Osozawa, K., Ninomiya I., Adriyanti, D.T. 2012. New social value on the establisment of cemara udang (Casuarina equisetifolia) in southern coast of Yogyakarta. Procedia Environmental Sciences, (17) 2012: pp 79-88. mitigation by coastal vegetation considering the effect of tree breaking. Journal of Coastal Conservation, 16(1) 2012: pp 111121.

[UPT] Unit Pelaksana Teknis Pantai Lombang. 2015. Data Wisata. Tidak diterbitkan

Yulianda F., A. Fahrudin, A.A Hutabarat, S. Harteti., Kusharjani, H.S., Kang., L Adrianto. 2010. Pengelolaan Pesisir dan Laut secara Terpadu. Pusdiklat Kehutanan-Departemen Kehutanan Republik Indonesia: Bogor.

Zografos, C., Allcroft, D. 2007. The environmental values of potential ecotourists: a segmentation study. Jurnal of Sustainable Tourism, 15(1) 2007: pp 4466. 